\title{
Use of LOM and EBSD to Identify Bainite in Complex Phase Steel
}

Renan de Melo Correia Lima ${ }^{1}$, Julio Spadotto ${ }^{2}$ and Fernando Cosme Rizzo ${ }^{3}$

${ }^{1}$ Department of Chemical and Materials Engineering, Pontifícia Universidade Católica do Rio de Janeiro (PUC-Rio), Rio de Janeiro, Rio de Janeiro, Brazil, ${ }^{2}$ Department of Chemical and Materials Engineering, Pontifícia Universidade Católica do Rio de Janeiro (PUC-Rio), United States, ${ }^{3}$ Department of Chemical and Materials Engineering, Pontifícia Universidade Católica do Rio de Janeiro (PUC-Rio), Brazil

Complex-Phase (CP) steels are a class of Advanced Hight Strength Steels (AHSS) that has come as an alternative to the traditional Dual-Phase ones ${ }^{1-5}$. CP steels are constituted of a bainitic matrix, with ferrite, martensite and retained austenite. With such a complex microstructure, the identification (ID) and quantification of the phases are a challenge in this type of steel. Dilatometry is among the best techniques to understand the development of a microstructure, and has been consistently used for that ${ }^{6-8}$. However, when characterizing a processed steel, dilatometry is not a good choice, since it is a characterization that needs to be done during the processing of the steel.

Color etching ${ }^{9}$ and Electron Backscatter Diffraction (EBSD) ${ }^{5,10,11}$ can be used to directly identify ferrite, martensite, and retained austenite, but not bainite. One alternative solution would be an indirect bainite ID using Light Optical Microscopy (LOM) and EBSD data. In this work, the combination of these two techniques was used aiming to quantify the bainite amount of a CP1100 steel. A color etching using a $2 \%$ Nital solution followed by a $10 \% \mathrm{Na}_{2} \mathrm{~S}_{2} \mathrm{O}_{5}$ water solution was used to reveal the microstructure for LOM imaging. This anodic surface etching reveals a whitish ferrite region, a brown/dark-brown martensitic/bainitic region and a black retained austenite (Figure 1A). The LOM image was segmented using the Waikato Environment for Knowledge Analysis (WEKA) segmentation from the FIJI software (Fig. 1B). Imaging was performed at Instituto Nacional de Tecnologia (INT, Brazil) using an Olympus BX51M capable of doing 2000x optical magnification

Considering that bainite is a microconstituent consisting of ferrite and carbides ${ }^{12}$, during the EBSD analysis both ferritic and bainitic regions are indexed as ferrite. Therefore, assuming that the ferrite quantification performed using LOM is reliable and its distribution is homogeneous, subtracting the amount of ferrite measured in the LOM images from that obtained through EBSD maps resulted in an estimated bainite percentage of $22,3 \%$ in the CP steel, as indicated in Table 1 (bainite I). To improve the sampling precision, several different regions were observed; Figure 2 shows an example of the EBSD analysis, which were performed in a SEM Jeol 7100FT equipped with an Oxford Nordlys Max 2 EBSD detector located at LabNano in the Centro Brasileiro de Pesquisas Físicas (CBPF).

An additional estimation of the bainite percentage was derived from the martensite/bainite amount (bainite II) obtained with LOM. In this case, the percentage of martensite obtained with EBSD was deducted from the martensite + bainite amount measured using LOM, producing a value of 22,8\%.

Finally, another alternative to bainite ID is to consider the deformation in the ferritic microstructure. It is expected a higher dislocation density ${ }^{11}$ which could be seen using the kernel average misorientation (KAM) map and the grain orientation spread. The bainite can then be segmented as the deformed region. Figure 2 D-F shows that alternative segmentation with a $20.3 \%$ of bainite ID. Table 1 shows the final quantification found by LOM and EBSD. These results are in agreement with dilatometric analysis. 
Phase

Retained Austenite

Ferrite + Bainite

Ferrite

Bainite I

Martensite + Bainite

Martensite

Bainite II
LOM \%

$0.8 \pm 0.24$

$53.9 \pm 3.8$

$45.3 \pm 3.6$
$22.3 \pm 1.2$

$22.5 \pm 1.48$

$21.8 \pm 1.5$

The authors would like to acknowledge the companies, funding entites and research centers involved in this work: Pontifícia Universidade Católica do Rio de Janeiro (PUC-RIO); Companhia Siderúrgica Nacional (CSN); Centro Brasileiro de Pesquisas Física (LABNANO/CBPF); Instituto Nacional de Tecnologia (INT); Coordenação de Aperfeiçoamento de Pessoal de Nível Superior (CAPES); Conselho Nacional de Desenvolvimento Cientifico e Tecnológico (CNPq) and the Fundação Carlos Chagas Filho de Amparo a Pesquisa do Estado do Rio de Janeiro (FAPERJ).

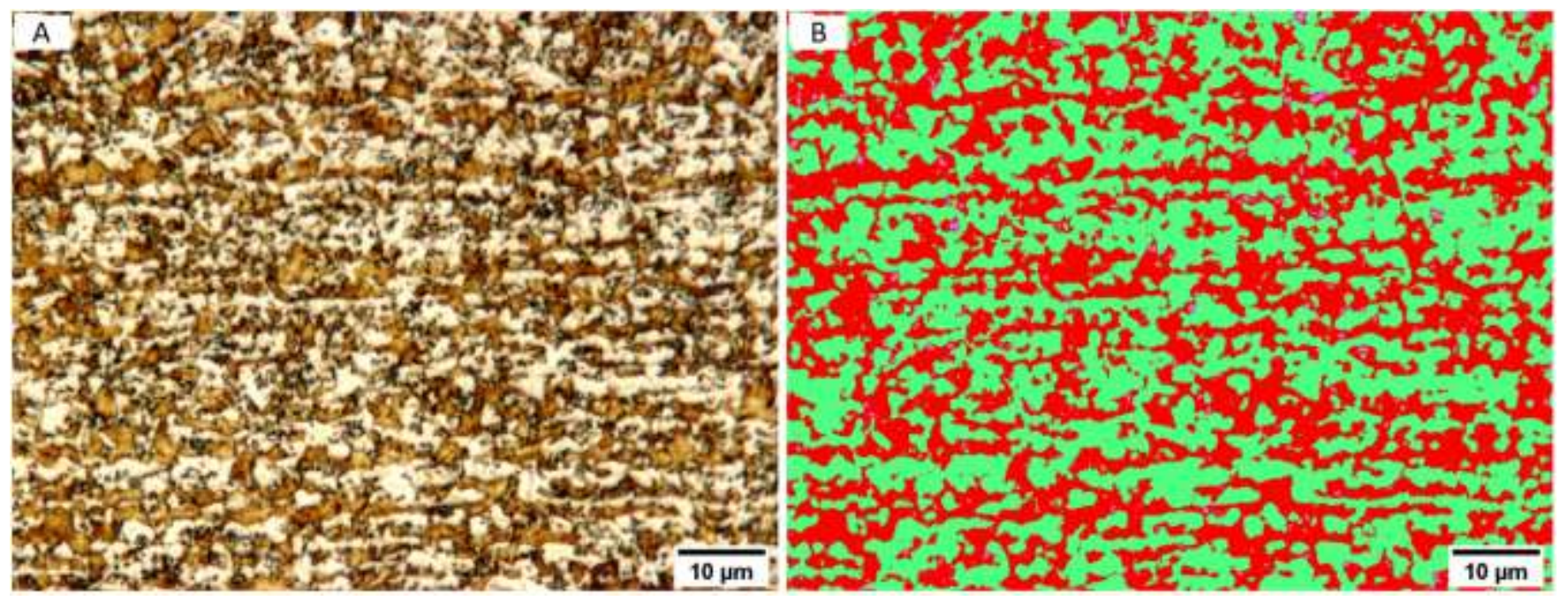

Figure 1. LOM image of the CP1100 steel and its WEKA segmentation. A) Etched surface: whitish = ferrite, brown/dark brown = martensite/bainite, black = retained austenite and B) Segmented image, green $=$ ferrite, red $=$ martensite/bainite, purple $=$ retained austenite . 

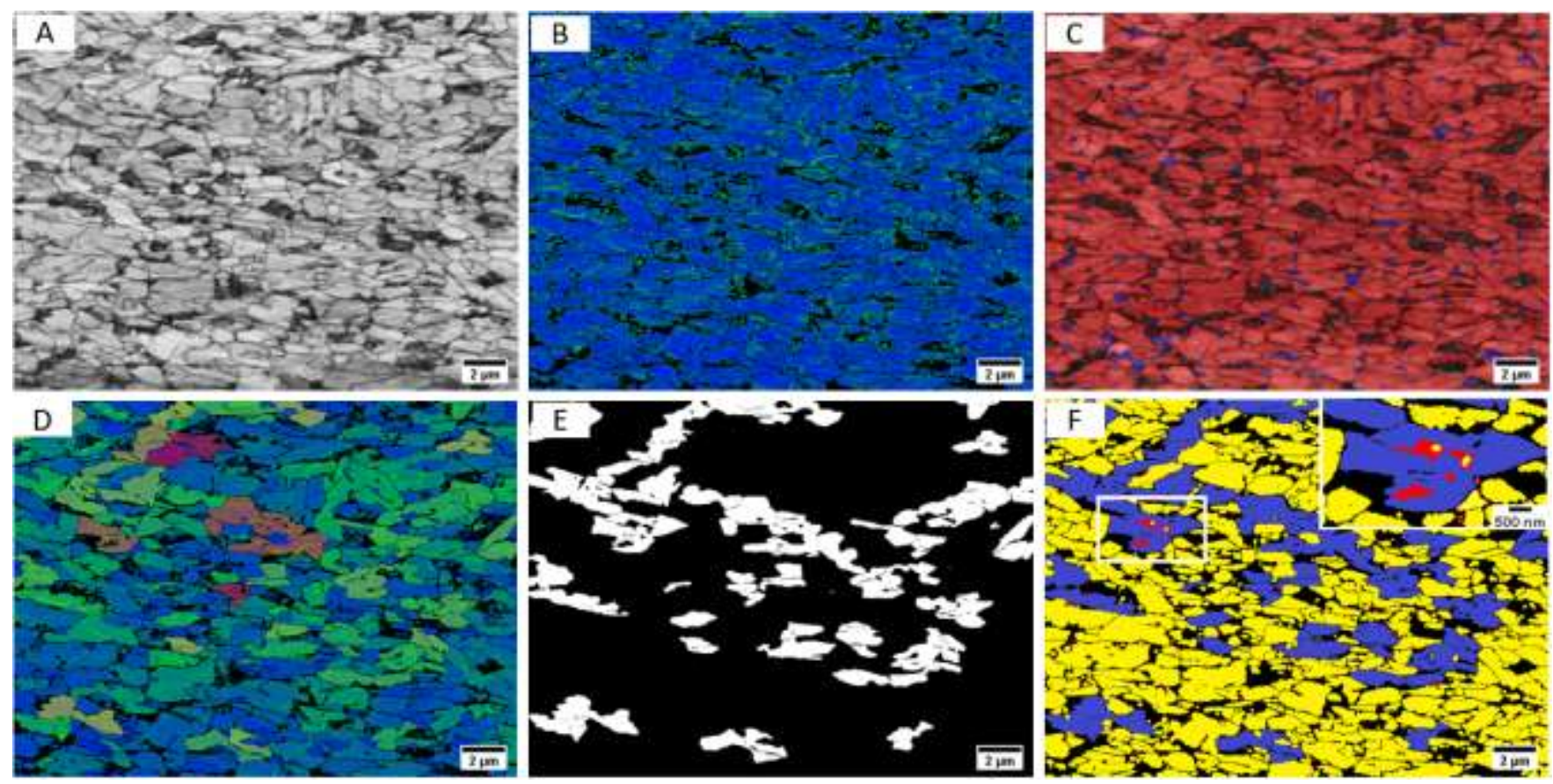

Figure 2. EBSD analysis of the CP1100. A) Image Quality map B) Kernel Average Misorientation C) Band Slop + Phase ID, red $=$ ferrite/bainite, blue $=$ retained austenite and black = martensite (zero solution) D) Kernel Average Misorientation + Grain Orientation Spread map E) Segmented bainitic region F) Fully segmented map with zoomed in area, yellow = ferrite $(54.7 \%)$, blue = bainite $(20.3 \%)$, red $=$ retained austenite $(1.8 \%)$ and black $=$ martensite $(18.3 \%)$.

\section{References}

1. $\quad$ Fleeson, W. et al. No \{Title\}. J. Pers. Soc. Psychol. 1, 1188-1197 (2017).

2. Karelova, A. et al. Hole Expansion of Dual-phase and Complex-phase AHS Steels - Effect of Edge Conditions. Steel Res. Int. 80, 71-77 (2009).

3. Zajac, S., Schwinn, V. \& Tacke, K. H. Characterisation and Quantification of Complex Bainitic Microstructures in High and Ultra-High Strength Linepipe Steels. Mater. Sci. Forum 500-501, 387-394 (2005).

4. Martin, P., Unruh, K., Chottin, J. \& Hug, E. Damage mechanisms in multiphased steels with a bainitic matrix under various mechanical loading paths. Procedia Manuf. 15, 1557-1564 (2018).

5. Li, X., Ramazani, A., Prahl, U. \& Bleck, W. Quantification of complex-phase steel microstructure by using combined EBSD and EPMA measurements. Mater. Charact. 142, 179-186 (2018).

6. Mesplont, C., Vandeputte, S. \& De Cooman, B. C. Dilatometric study of the effect of soluble boron on the continuous and isothermal austenite decomposition in 0.15C-1.6Mn steel. Zeitschrift fuer Met. Res. Adv. Tech. 93, 11081118 (2002).

7. Zhao, J. Z., Mesplont, C. \& Cooman, C. De. Calculation of the phase transformation kinetics from a dilatation curve. J. Mater. Process. Technol. 129, 345-348 (2002).

8. Zhao, J. Z., Mesplont, C. \& De Cooman, B. C. Quantitative analysis of the dilatation during an isothermal decomposition of austenites. Mater. Sci. Eng. A 332, 110-116 (2002).

9. Hairer, F. et al. Etching techniques for the microstructural characterization of complex phase steels by light microscopy. Int. Dr. Semin. ... 50-54 (2008).

10. Zhao, H., Wynne, B. P. \& Palmiere, E. J. A phase quantification method based on EBSD data for a continuously cooled microalloyed steel. Mater. Charact. 123, 339-348 (2017).

11. Garcia, C. I., et al. New method of characterizing and quantifying complex microstructures in steels. in Materials and Manufacturing Processes 25, 33-40 (2010).

12. Bhadeshia, H. K. D. H. \& Christian, J. W. Bainite in steels. Metall. Trans. A 21, 767-797 (1990). 